only to confirm the diagnosis of oculosympathetic paresis.' In both types of lesion inhibiting the uptake of noradrenaline will have no effect; as little to none has been released. In addition, the aim of Thompson and Mensher's paper, ${ }^{2}$ which Dr Wimalaratna and colleagues cite, was to promote the use of $1 \%$ hydroxyamphetamine as a test to distinguish between preganglionic and postganglionic Horner's syndrome. (It dilates the pupil in patients with preganglionic lesions but not in those with the postganglionic lesions, as it stimulates the release of noradrenaline from terminals only in the intact postganglionic neuron.) Thompson and Mensher also state that dilute adrenaline is a poor test for the supersensitivity of the postganglionic lesion but that $1 \%$ phenylephrine is more effective.

In the case presented by Dr Wimalaratna and colleagues, therefore, although there seems little doubt of the presence of a Horner's syndrome, the $1 \%$ hydroxyamphetamine test would have dilated the pupil of the preganglionic lesion, showing the integrity of the postganglionic neuron and dilator muscle of the iris, which had not been shown to be intact by the tests used by Dr Wimalaratna and colleagues.

Department of Ophthalmology,

STEPHEN A VernoN

University Hospital

Nottingham NG7 2UH

1 Glazer JS. The pupil and accommodation. In: Glazer JS. Neuro ophthalmology. New York: Harper and Rowe, 1978:178.

2 'Thompson HS, Mensher JH. Adrenergic mydriasis in Horner' syndrome. Am f Ophthalmol 1971;72:472-80.

AUTHOR'S REPLY - The purpose of our paper (6 June, p 1463) was to establish the relation between herpes zoster of the first and second thoracic segments and ipsilateral Horner's syndrome.

Mr Vernon, however, queries the validity of the pharmacological tests of pupillary function. Our reference to the cocaine test comes from the work of Jaffe, ${ }^{1}$ who clearly states that cocaine dilates the pupil when the lesion is "central" (first neurone) and causes no change when it is peripheral (postganglionic). A lesion in the central neurone produces partial loss of tone in the sympathetic pathway-enough to produce symptoms of Horner's syndrome and to release small amounts of noradrenaline at the dilator muscle of the iris. These small quantities of noradrenaline are sufficient to cause partial mydriasis with cocaine, which inhibits reabsorption of noradrenaline at the nerve endings.

$\mathrm{Mr}$. Vernon quotes the book Neuro-ophthalmology, ${ }^{2}$ which in turn quotes the work of Stanley Thompson, ${ }^{34}$ who merely promotes the hydroxyamphetamine test as a "new and better way to distinguish pre-from post-ganglionic sympathetic defects" in Horner's syndrome. In the paper by Thompson and Mensher pupillary response to cocaine in 12 patients with unilateral Horner's syndrome showed partial dilatation in the central group compared with no dilatation in the postganglionic group. The normal pupil, however, unlike the affected side, dilated fully. The paper by Grimson and Thompson unfortunately does not provide sufficient details about the pupillary sizes during the cocaine test.

Hydroxyamphetamine, which causes release of noradrenaline from the nerve endings, is a more sensitive test, but it will not differentiate pseudoHorner's syndrome from true preganglionic ocular sympathetic paresis where rapid mydriasis would result in both these conditions. The hydroxyamphetamine test is, therefore, of little value if used as the sole measure of pupillary function in a suspected case of Horner's syndrome.

Phenylephrine is a general mydriatic and causes full dilatation even in the normal pupil. The adrenaline test may occasionally be insensitive, ${ }^{3}$
Reactions to tests of pupillary function

\begin{tabular}{|c|c|c|c|}
\hline Condition & $\begin{array}{c}1 \% \\
\text { Adrenaline }\end{array}$ & $\begin{array}{c}4 \% \\
\text { Cocaine }\end{array}$ & $\begin{array}{c}1 \% \\
\text { Hydroxy- } \\
\text { amphetamine }\end{array}$ \\
\hline $\begin{array}{l}\text { Normal } \\
\text { Pseudo-Horner's } \\
\text { syndrome }\end{array}$ & $\begin{array}{l}\text { No change } \\
\text { No change }\end{array}$ & $\begin{array}{l}\text { Full dilatation } \\
\text { Full dilatation }\end{array}$ & $\begin{array}{l}\text { Full dilatation } \\
\text { Full dilatation }\end{array}$ \\
\hline $\begin{array}{l}\text { Central Horner's } \\
\text { syndrome }\end{array}$ & No change & $\begin{array}{l}\text { Partial } \\
\text { dilatation }\end{array}$ & Full dilatation \\
\hline $\begin{array}{l}\text { Postganglionic } \\
\text { Horner's } \\
\text { syndrome }\end{array}$ & $\begin{array}{l}\text { Full } \\
\text { dilatation }\end{array}$ & No change & No change \\
\hline $\begin{array}{c}\text { Primary iris } \\
\text { disease }\end{array}$ & No change & No change & No change \\
\hline
\end{tabular}

*Hydroxyamphetamine (Paredrine) is not available in the United Kingdom, except on a "named patient" basis.

but for practical purposes a combination of $0 \cdot 1 \%$ adrenaline, $4 \%$ cocaine, and $1 \%$ hydroxyamphetamine (if available) would provide the best guide to the level of the lesion in patients with Horner's syndrome (table)

Regional Centre for Neurology and

H S K WimalaratNa

Neurosurgery,

Oldchurch Hospital

Romford RM7 0BE

Jaffe NS. Localisation of lesions causing Horner's syndrome. Arch Ophthalmol 1950;44:710-28.

2 Glazer JS. The pupil and accommodation. In: Glazer JS. Neuroophthalmology. New York: Harper and Rowe, 1978:178.

3 Thompson HS, Mensher JH. Adrenergic mydriasis in Horner's syndrome. Am $\mathcal{O}$ Ophthalmol 1971;72:472-80.

4 Grimson BS, Thompson HS. Drug testing in Horner's syndrome. In: Glaser JS, Smith JL, eds. Neuro-ophthalmology symposium. Vol 8. St Louis: Mosby, 1975:265-70.

\section{Prediction of resources needed for treatment of renal failure}

SIR,-The useful model proposed by Dr I T Wood and colleagues suggests that if 40 patients per million population start renal replacement treatment each year current funding must be increased threefold. Our experience in north east Scotland, however, suggests that the actual resources required are likely to be much greater. In 1986, 33 patients in Grampian region started renal replacement treatment-the equivalent of 66 patients per million population-and the total number of patients reached 144 , or 288 per million population. Current local trends indicate that the figures will continue to rise.

Inevitably, with this high acceptance rate many more "high risk" patients receive treatment. Furthermore, renal transplantation rates have not kept pace with demand. These factors have led to a corresponding increase in mean cost per patient. Our experience therefore suggests that the resources required will be seriously underestimated if cost calculations continue to be based on a yearly acceptance rate of 40 patients per million population.

D J PROPPER

G R D CATTO N EDWARD

Aberdeen Royal Infirmary

Aberdeen AB9 2ZB

SIR,-Though we were pleased to read the account by Dr I T Wood and colleagues of quantitative techniques being used to predict resource requirements for patients with renal failure ( 6 June, p 1467), it is disappointing that the estimates were based on false assumptions and failed to take account of recent developments in the use of simulation techniques. ${ }^{12} \mathrm{We}$ are currently developing these further in a cooperative research project with the European Dialysis and Transplant Association, funded by the Medical Research
Council. We would like to draw attention to just four of the main weaknesses of the paper by $\mathrm{Dr}$ Wood and coworkers.

Firstly, to operate the flow graph technique the authors find they have to consider continuous ambulatory peritoneal dialysis as a "substitute for independent home dialysis." Such an assumption is an oversimplification because the resource requirements are very different; patients receiving continuous ambulatory peritoneal dialysis do not need hospital haemodialysis facilities or home conversions. Moreover, continuous ambulatory peritoneal dialysis is used for a much wider range of patients than home dialysis, including older and more dependent patients. ${ }^{3}$

Secondly, Dr Wood and colleagues suggest that the availability of transplants is unconstrained. In view of the current shortages of cadaver kidneys, this major simplification requires little comment.

Thirdly, only "steady state" results are given, which are for a distant and unspecified point in time and are based on the assumption that treatment policies and survival figures will not change in the interim.

Fourthly, even if we accept (which we do not) the authors' methods and results, they omit crucial information about the sources and accounting basis of the costs that underlie their conclusions, and to which they may be very sensitive.

Health authorities will have to plan for the increasing demand for treatment and need a good predictive model for this purpose. The modelling techniques described in this paper have forced the authors to make unrealistic assumptions and to predict over an unknown time scale. This unfortunately undermines confidence in the results. Markov models and their derivatives have proved inadequate time and again, ${ }^{4}$ and we are sure that the answer lies in the use of the much more flexible discrete simulation techniques. ${ }^{2}$

Ruth Davies

HuW DAVIES

Department of Mathematical Sciences and Computing,

South Bank Polytechnic,

London SEI OAA

Davies R. An interactive simulation in the health service. Fournal of the Operational Research Society 1985;36:597-606.

Davies R, Davies T. Using simulation to plan health service resources. $\mathcal{F} R$ Soc Med 1986;79:154-7.

3 Taube D, Winder EA, Ogg CS, et al. Successful treatment of middle aged and elderly patients with end stage renal failure. BrMed f 1983;286:2018-20.

Davies R. An assessment of models of a health system. Foumal of the Operational Research Society 1985;35:679-87.

\section{Should sympathomimetics be available over} the counter?

SIR,-No one would seek to minimise the harm caused to both physical and mental health by the abuse of amphetamines, and we should therefore be grateful to Dr Andrew Whitehouse (23 May, p 1308) for his reminder of the dangers of these drugs. Dr Whitehouse's suggestion, however, that the abuse of sympathomimetics in the United Kingdom might be prevented (or at any rate reduced) by making them available only on prescription merits further comment.

In the United States medicines are classified as either prescription only or over the counter medicines, the second category being available from any retail outlet, including supermarkets, and by mail order. Few of the states have an intermediate class of medicines that corresponds to our class $\mathrm{P}$ - that is, saleable only from pharmacies, the sale being supervised by a pharmacist. In the United Kingdom medicines that contain sympathomimetics are available either on prescription or from a pharmacy. Pharmacists in the United Kingdom have long been aware of the 
potential danger of such medicines and have taken steps to restrict their availability to the public except when required for genuine medical purposes. The council of the Pharmaceutical Society of Great Britain first warned the profession of the dangers of these drugs in March $1950^{1}$ and issued a reminder in $1957 .{ }^{2}$

A second point worthy of mention is that there is no evidence to support the concept that the misuse of medicines is minimised by making them available only on prescription. Perhaps the most widely misused drugs are barbiturates, which have been responsible for more than $\mathbf{4 2 0 0 0}$ deaths in England and Wales since their introduction in 1906. All but 640 of these deaths occurred after 1936, when barbiturates were made a prescription only medicine. Moreover, although amphetamine was voluntarily treated as a prescription only medicine by most pharmacists in 1937, it was not made legally so until 1956. The misuse of amphetamines by teenagers increased greatly in the mid-1960s, many teenagers obtaining the drug from supplies prescribed as slimming pills or "pep pills" for their mothers, many of whom were also dependent on amphetamines. ${ }^{3}$ The current epidemic use of benzodiazepines cannot be due to irresponsible sales by pharmacists because they were made a prescription only medicine soon after they were launched on to the market in the early 1960 s.

The current epidemic of amphetamine misuse in parts of the United Kingdom has, I suggest, nothing to do with doctors, pharmacists, pharmaceutical manufacturers, or wholesalers. Most of today's amphetamine misusers inject the drug intravenously, though some take it intranasally. Most of this material has been made illicitly and provides substantial profits for the "bathtub chemists" responsible for its manufacture. It is unlikely to be supplanted by the less satisfying and more expensive $\mathbf{P}$ classified proprietary products available from pharmacies, even if pharmacists were prepared to sell them.

Members of the public occasionally have a medical need for drugs such as the sympathomimetics. It seems heavy handed to insist that they see a doctor to obtain a prescription for the drug merely to prevent a few misusers from obtaining access to it.

\section{University of Wales Institute of Science and Technology, Cardiff CF1 3NU}

IVOR HARRISON

1 Council of the Pharmaceutical Society of Great Britain. Slimming preparations and "cold cures." Pharmaceutical foumal 1950;1: 182.

2 Council of the Pharmaceutical Society of Great Britain. Slimming drugs. Pharmaceutical foumal 1957;2:125.

3 Advisory Committee on Drug Dependence. The amphetamines and lysergic acid diethylamide (LSD). London: HMSO, 1970: $7-9$.

\section{Cough associated with captopril and enalopril}

SIR,-Drs D M Coulter and I R Edwards provide further support for our suggestion that the cough associated with the use of converting enzyme inhibitors is found more commonly in women. ${ }^{12}$ Like Drs Coulter and Edwards, we noted that the onset of cough may be delayed for weeks, or occasionally several months, after treatment is started. Unlike them, however, we find that the period of recovery is of similar duration, and we believe that the lack of a close relation between the symptoms and the period of treatment may, at least partly, explain the long delay between the introduction of this class of drug and the recognition of cough as an adverse effect of treatment.

Our experience suggests that the incidence of this side effect may be closer to the $10 \%$ reported elsewhere ${ }^{3}$ though the cough is not always severe enough to merit withdrawal of treatment and indeed, in patients with resistant hypertension may be preferred to the adverse effects of other drugs. We have also found in some cases that reducing the dose alleviates the symptoms. This does not necessarily conflict with the finding of Drs Coulter and Edwards that patients with cough were receiving similar doses of converting enzyme inhibitors to those not suffering from this side effect.

With regard to the cause of the cough, Drs Coulter and Edwards suggest that bradykinin or prostaglandin $\mathrm{E}_{2}$ may play a part. The recen report by Nicholls and Gilchrist, describing six patients in whom treatment with the prostaglandin inhibitor sulindac improved or cleared the cough, would tend to support this hypothesis.

D J WEBB

N BENJAMIN

J G COLLIER

St George's Hospital Medical School,

B F ROBINSON

London SW17 0RE

1 Webb D, Benjamin N, Collier J, Robinson B. Enalapril induced cough. Lancet 1986;ii:1094.

2 Inman WHW. Enalapril induced cough. Lancet 1986;ii: 1218. Town GI, Hallwright GP, Maling T, O'Donnell TV. Angiotensin
converting enzyme inhibitors and cough. NZ Med f 1987;100 161-3.

Nicholls MG, Gilchrist NL. Sulindac and cough induced by converting enzyme inhibitors. Lancet 1987; ;:872.

\section{Nuclear magnetic resonance imaging}

SIR,-Few radiologists have the experience usefully to add to Professor R E Steiner's admirable review of nuclear magnetic resonance imaging (20 June, p 1570). For those interested in musculoskeletal disease magnetic resonance imaging seems to be an essential tool in the study of the soft tissues, joints, spine, etc. Preliminary assessments of the economic implications of this are interesting and potentially cost saving.

As an example, Tyrrell has compared magnetic resonance imaging of the knee with diagnostic arthroscopy. The intra-articular findings were very similar, with imaging also showing extra-articular anatomy (findings presented at European congress on radiology, Lisbon, 1987). The magnetic resonance examination, using a fast sequence and three dimensional volume imaging, may be completed in 20 minutes. Thus the throughput, even including more complex examinations, could be 12-20 daily, so that the cost per patient would be of the order of $£ 60-100$. These figures are estimates based on the real costs of staffing and depreciation of a $1 \cdot 0$ tesla system.

The costs of diagnostic arthroscopy are thought to be much higher, the time taken overall much greater, and the possible morbidity not unimportant. As a result, in some centres in the United States magnetic resonance imaging is the procedure of choice for first assessment of problem knees. Furthermore, this particular example of efficient use of resources is not unique.

J C MACLARNON D J WILSON

Nuffield Orthopaedic Centre,

Oxford OX3 7LD

Cervical smears: new terminology and new demands

SIR,-Professor P P Anthony and Dr R M Kelly

(27 June, $p$ 1687) claim that they have halved the expected number of cases of invasive carcinoma of the cervix in Exeter and North Devon by screening only half of the population at risk. This would be a remarkable achievement if it were true. The data that they present, however, bear other interpretations.

Professor Anthony and Dr Kelly detected 518 potentially lethal lesions by cytological screening and estimate that 207 of these would have progressed to invasive cancer. Of these cases, 145 would have occurred in Exeter. In the same period in Exeter 152 cases of cervical cancer were diagnosed. Only $44 \%$ of these cases, however, were from the unscreened or inadequately screened population, the rest occurring in the screened group. Thus the unscreened population generated around 67 cases, while the screened population produced 85 and, according to the authors, would have produced 230 cases in the absence of the screening programme. Obviously, there is a flaw in this argument, as it is well known that cytology screening programmes select the low risk rather than the high risk half of the population.

There are two possible explanations for these findings. The first is that most of the cases of intraepithelial neoplasia will not progress to invasive cancer. If this is true it carries important consequences for immune surveillance in carcinogenesis. The second possibility is that most cases of intraepithelial neoplasia would progress over a longer period and that we can thus expect a large increase in the incidence of invasive carcinoma particularly in the unscreened population, in coming years. If the second explanation is correct then the views expressed by Professor Anthony and Dr Kelly are unfortunately complacent.

J A MORRIS

Department of Pathology, Lancaster Moor Hospital, Lancaster LA1 3JR

\section{The art of debate?}

SIR,-On the last day of the recent annual representative meeting in Bristol, when the section on the acquired immune deficiency syndrome was being debated, one of the priority motions was so altered by amendments that the gist of the original motion was reversed. I refer to motion 364 . The final amendment was suggested after a short adjournment and approved after further debate.

There was less time for formal debate on the much amended motion than was spent on the somewhat chaotic, and at times heated, debate on the amendments. The use of amendments in debate may serve as a spoiling tactic and may stifle the more open style of those representatives less familiar with the procedures. It was all very democratic, but the final form of the amended motion was so different from the original that if anyone had intended to vote for the motion as it stood on the agenda paper they would have had to vote against the amended motion merely to express disapproval, as the meaning of the motion was so completely changed that it lost the sense of the original. Even the television crews were baffled and gave up on this one.

Perhaps standing orders should be revised again to place certain restraints on amendments to prevent motions being turned inside out and also strictly to limit the time allowed for debating amendments, with extra time being reserved for amendments so that they do not count against other motions in the same section. Then there might be time to debate some of the other motions on the agenda that at present are lost through lack of time.

Perhaps I am carping; perhaps I am mistaken in my understanding; but I think that I am not alone in thinking as I do.

David Parkes BoweN

Leicester LE3 8GS 